\title{
Gain of Chromosome 1q21
}

National Cancer Institute

\section{Source}

National Cancer Institute. Gain of Chromosome 1921. NCI Thesaurus. Code C129571.

A cytogenetic abnormality that refers to allelic gain within the chromosomal region 1 q21. 